\title{
Development and validation of extension strategies for effective management of reproductive problems of dairy animals
}

\author{
Diksha Patel and K Ponnusamy
}

Received: 20 December 2018 / Accepted: 05 February 2019 / Published online: 18 April 2019

(c) Indian Dairy Association (India) 2019

\begin{abstract}
Reproductive problems in dairy animals emerged as prime concern for farmers due to their significant effect on the profitability and sustainability of dairy ventures in India. The present study was undertaken to assess the major reproductive problems of dairy animals as well as to develop and validate the extension strategies for managing reproductive problems. A total of 60 respondents from three villages viz Dilawara, Chundipur and Dhakwada of Karnal district were selected through simple random sampling. Data were gathered through structured interview schedule from dairy farmers who had at least one milch animal. Study revealed that repeat breeding, anestrous, retention of fetal membrane and prolapse were the major reproductive problems of dairy animals as perceived by 46.67, 36.67, 28.33 and 26.67 per cent of respondents respectively. Among 14 selected extension strategies, development and demonstration of video on specific reproductive issues with Rank Based Quotient (RBQ) value of 81.19 and preparation of extension literature with RBQ value of 72.38 were found to be the two best strategies for faster dissemination of information on management of reproductive problems. The mean knowledge gain was found to be 10.75 per cent, 13.28 per cent and 15.23 per cent after exposure to different treatments i.e. booklet, video and both (video+booklet) respectively in the study villages. This explains the effectiveness of extension strategies and warrants the extension personnel to
\end{abstract}

Diksha Patel $(\bowtie)$, Ponnusamy

Dairy Extension Division, ICAR-National Dairy Research Institute,

Karnal 132 001, Haryana, India

E-mail:pateldiksha279@gmail.com contextualise and deploy appropriate combinations of different extension strategies in order to improve the information delivery system.

Keywords: Extension strategies, Profitability, Reproductive problems, Rank Based Quotient

\section{Introduction}

Reproductive problems in dairy animals severely affect the profitability of dairy ventures. The major reproductive problems having direct impact on reproductive performance of dairy animals were abortion, dystocia, retained placenta, metritis, prolapse, anoestrus and repeat breeding (Lobago et al. 2006). These reproductive problems and associated infertility among cattle and buffalo pose considerable economic loss to farmers in terms of low returns and veterinary expenses. The presence of the reproductive problems result in considerable economic loss to the dairy industry due to lesser number of calves born, slower uterine involution, prolonged inter-conception and calving interval, early depreciation of potentially used cows, decreased milk yield per lactation as well as overall lifetime production, and increased costs due to veterinary services and earlier culling of cows (Lobago et al. 2006).

Anestrous and repeat breeding in bovines are the two most serious reproductive problems affecting 30-40 per cent of the total cattle and buffalo population. This results in a loss of 20-30 million tonnes of milk annually which translates to economic loss of nearly Rs. 50,000 crores annually. At micro-level, a farmer incurs a loss of at least Rs. 2000-2500/animal by missing of one estrous cycle (ICAR, 2013). Delayed age at sexual maturity (3133 months in Murrah against 18-19 months in Mediterranean buffaloes), poor expression of heat symptoms and uterine infection still remains as major issues in achieving high reproductive efficiency in buffaloes in India, (Srivastava et al. 2015). Each year an average of 20-25 per cent of dairy cows are culled due to poor reproductive performance (Keown et al. 2006). Total losses due to reproductive problems in buffaloes were 39 per cent of all the losses incurred by various diseases. Buffalo suffering from abortion had a significant effect on calving interval and highly significant effect on service period. Dystocia affected 
animals required significantly greater number of services for conceiving. Metritis had highly significant effect on service period and service per conception (Khan et al. 2009). Milk yield has been reported to decrease by $239 \mathrm{Kg}$ for retained fetal membrane (RFM), $181 \mathrm{Kg}$ for stillbirth, $173 \mathrm{Kg}$ for dystocia and $98 \mathrm{Kg}$ for metritis, (Simerl et al. 1992). Pawshe et al. (2011) reported an estimated loss from anestrus around Rs.193.00 per day in cow and Kumar et al. (2013) reported Rs. 372.90 per day in buffalo. The estimated loss due to decreased milk production and treatment cost of retained fetal membrane is Rs. 12,000 per cow (Kumaresan et al. 2012).

These problems, if not addressed properly, lead to severe economic loss to dairy farmers. Thus, it is important to educate the farmers on different aspects of managing reproductive problems in dairy animals, where different extension strategies can play a significant role in facilitating rapid, efficient and cost effective sharing of knowledge. Appropriate extension strategies are required to educate the farmers in order to minimise the economic loss of farmers due to these problems. At the same time, developed extension stategies should be effectively analysised for their potential to disseminate the requitred information because developed technologies are mainly meant for increasing knowledge of dairy farmers regarding management of reproductive problems, but this will not have any impact unless the technologies are well conceived and understood by its end users. Thus keeping these scenarios in view, the present study was undertaken to assess the major reproductive problems of dairy animals as well as to develop and validate the extension strategies for improving the information delivery system and address the reproductive problems efficiently at farm level.

\section{Materials and methods}

The present study was undertaken purposively in Karnal district of Haryana. A total of 60 respondents from three villages namely namely Dilawara, Chundipur and Dhakwada of Karnal district were selected through simple random sampling method. The selected respondents had at least one adult milch animal. Data were collected through personal interview method with the help of structured interview schedule.

Extension strategy in this study refers to 'set of actions aiming at managing reproductive problems in dairy animals'. Based on the literature review and expert consultation, 14 possible strategies were identified in the field of management of reproductive problems. About 30 experts hailing from Dairy Extension, LPM, Animal Nutrition Division of NDRI, Karnal, Extension Education Institute (EEI), Nilokheri, veterinary officers of different state department of animal husbandry were requested to rank the 14 strategies according to their appropriateness for managing reproductive problems in dairy animals.
Rank based Quotient (RBQ) method was used for ranking the most appropriate extension strategy for faster dissemination of information regarding management of reproductive problems in dairy animals. According to response of experts, various extension strategies were ranked accordingly.

$$
\mathrm{RBQ}=\mathrm{f}_{\mathrm{i}}(\mathrm{n}+1-\mathrm{i}) / \mathrm{Mxn} \times 100
$$

Where,

$f_{i}=$ Number of respondents reporting a particular extension strategy under $\mathrm{i}^{\text {th }}$ rank

$$
\begin{aligned}
& \mathrm{M}=\text { Number of respondents } \\
& \mathrm{n}=\text { Number of extension strategies }
\end{aligned}
$$

Based on the Rank Based Quotient (RBQ) value one educational video and one booklet on management of reproductive problems in dairy animals was developed and effectiveness of developed booklet and video were assessed through Knowledge gain. English and English (1961) defined knowledge as a body of understood information possessed by an individual. Accordingly, the "Knowledge gain is operationalized as the amount of information and understanding, which gained by the respondents after exposure to extension strategies for reproductive management of dairy animals". For this purpose three villages Dilawara, Chundipur and Dhakwada from Karnal district of Haryana were identified. Then from each village, 20 respondents have been selected and were given three treatments viz. T1 (Booklet), T2 (Video) and T3 (Booklet+Video) respectively. The effectiveness of each strategy has been assessed by pre and post knowledge test and knowledge gain was assessed.

Knowledge gain $=$ post test score- pre test score

Constraints were measured and recorded on a 3-point continuum, viz. 'Very serious', 'Serious' and 'Not serious' and weighted mean score (WMS) method (Ponnusamy, 2006) was employed to rank the most serious constraints of dairy farmers as perceived by them.

\section{Results and discussion}

\section{Occurrence of major reproductive problems in dairy animals as perceived by farmers}

Respondents were asked to describe the occurrence of major reproductive problems and reported that repeat breeding, anestrous and retention of fetal membrane were the major reproductive problems of dairy animals as perceived by 46.67 , 36.67 and 28.33 per cent of respondents respectively (Table 1 ). The above finding were in line with finding of Meena and Malik (2009) who found that repeat breeding followed by anoestrus were prominent reproductive problems of dairy animals as 
reported by 68.66 and 28.66 per cent of respondents in Karnal district of Haryana. Further, prolapse, uterine infections, dystocia, cystic ovary, late sexual maturity, abortion and stillbirth were also occurred reproductive problems as reported by 26.67, 20.00, $15.00,10.00,10.00,6.67$ and 3.33 per cent of respondents respectively.

Repeat breeding was reported as most prominent problem of dairy animals. It was mainly due to the poor conception through artificial insemination (AI), which might be due to various reasons like poor quality of semen, untrained inseminators and farmers' inability to recognize the animals at proper time of heat for AI. There were number of factors could be attributed for the cause of repeat breeding such as climatic condition of the area, sub fertile bulls, endocrine imbalance, reproductive tract infections, communal use of bull for natural service and other managerial factors (Arthur et al, 1975).

Anestrous was found to be the second most serious problems in dairy animals. This was mainly due to imbalance feeding of dairy animals that resulted in mineral deficiencies. Silent heat, failure to detect heat symptoms and management factors were the other causes of anestrous in animals. Retention of fetal membrane was found to the third most serious problems. This might be due to the poor feeding of dairy animals, mineral deficiencies, pre-mature birth of calf, abortion, lack of tonosity in uterine muscles, uterine infections, etc. Prolapse was also found the fourth important reproductive problems of dairy animals especially in buffaloes. It usually associated with hypocalcaemia or milk fever, poor uterine tone, increased straining, more weight of the calf, tympany and

Table 1 Major reproductive problems in dairy animals as perceived by the respondents $(n=60)$

\begin{tabular}{lllc}
\hline S.no. & Reproductive problems & Frequency & Percentage \\
\hline 1 & Late sexual maturity & 6 & 10.00 \\
2 & Anestrous & 22 & 36.67 \\
3 & Repeat breeding & 28 & 46.67 \\
4 & Abortion & 4 & 6.67 \\
5 & Dystocia & 9 & 15.00 \\
6 & Retention of fetal membrane & 17 & 28.33 \\
7 & Stillbirth & 2 & 3.33 \\
8 & Prolapse (uterine/ vaginal) & 16 & 26.67 \\
9 & Cystic ovary & 6 & 10.00 \\
10 & Uterine infections & 12 & 20.00 \\
\hline
\end{tabular}

Table 2 Ranking of extension strategy for management of reproductive problems $(n=30)$

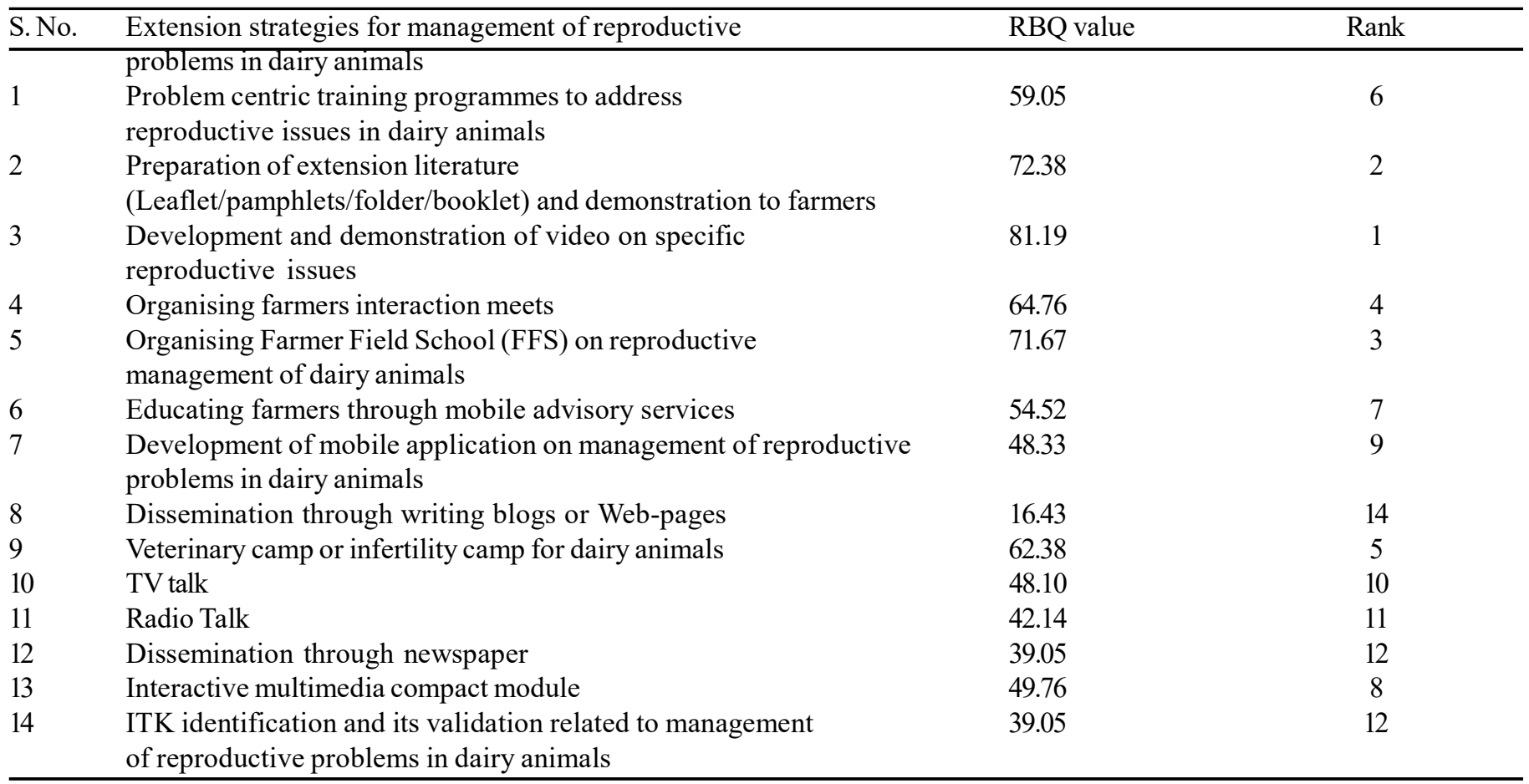


excessive estrogen content in the feed (Kumar and Yasotha, 2015).

Dairying is recognized as an important economic activity by farmers of Karnal, Haryana. Occurrence of these problems could lead to direct (loss of animal or calf) or indirect (losses due to reduction in milk production, higher calving interval, long service period, late onset of post-partum estrus etc.) economic loss to the farmers. Therefore, there is need to formulate effective extension strategies for managing these reproductive problems.

\section{Extension strategies for managing reproductive problems in dairy animals}

For managing reproductive problems, 14 possible extension strategies were identified and ranked according to the rank given by 30 experts of relevant field. Table 2 indicates that development and demonstration of video on specific reproductive issues was ranked first with RBQ value of 81.19 followed by preparation of extension literature for management of reproductive problems (72.38), organising Farmer Field School (FFS) on reproductive management of dairy animals (71.67), organising farmers interaction meets (64.67), veterinary camp or infertility camp for dairy animals (62.38) and problem centric training programmes to address reproductive issues in dairy animals (59.05) which were prioritized by experts in respect of technology dissemination. Whereas the dissemination through writing blogs or Web-pages (16.43), Dissemination through newspaper (39.05), ITK identification and its validation related to management of reproductive problems in dairy animals (39.05), radio talk and TV talk was given relatively less rank in respect of appropriateness in management of reproductive problems.

\section{Development and validation of Extension strategies}

Therefore, among all the 14 extension strategies, development and demonstration of video on specific reproductive issues and preparation of extension literature and demonstration to farmers

Table 3 Knowledge level of respondents in different treatments of extension strategies $(\mathrm{n}=60)$

\begin{tabular}{lllllll}
\hline S. No. & Extension strategies & Name of village & Before & After & \\
\cline { 4 - 6 } & & & Mean & SD & Mean & SD \\
\hline 1 & Booklet (T1) & Dilawara (n=20) & 46.70 & 6.95 & 56.05 & 6.34 \\
2 & Video (T2) & Chundipur (n=20) & 44.25 & 6.77 & 55.80 & 5.79 \\
3 & Video+ Booklet (T3) & Dhakwada (n=20) & 44.95 & 6.33 & 58.20 & 6.01 \\
\hline
\end{tabular}

Table 4 Effectiveness of extension strategies on Knowledge gain of respondents

\begin{tabular}{llllll}
\hline S. No. & Extension strategies & \multicolumn{3}{c}{$\%$ Knowledge } & t-value \\
\cline { 3 - 5 } & & Pre-test & Post-test & Knowledge gain & \\
\hline 1 & Booklet(T1) & 53.68 & 64.43 & 10.75 & $17.99^{* *}$ \\
2 & Video(T2) & 50.86 & 64.14 & 13.28 & $17.74^{* *}$ \\
3 & Booklet+Video(T3) & 51.67 & 66.90 & 15.23 & $25.11^{* *}$ \\
\hline
\end{tabular}

** Significant at 1 per cent level of significance

Table 5 Constraints of farmers in management of reproductive problems $(n=60)$

\begin{tabular}{lllc}
\hline S. No. & Constraints of farmers & WMS & Rank \\
\hline 1 & Non availability of AI and PD services at door step & 23.17 & 4 \\
2 & Lack of trained professionals for AI as well as for handling of & 22.00 & 6 \\
& reproductive problems in the locality & & 3 \\
3 & Poor conception rate with AI in dairy animals & 24.33 & 7 \\
4 & Economic loss due to decreased reproductive efficiency after & 22.00 & 1 \\
& occurrence of any reproductive diseases & 27.83 & 21.50 \\
5 & Poor Veterinary facilities during emergency hours & 2 & 8 \\
6 & Lack of opportunities to access knowledge about reproductive management of dairy animals & 25.17 & 11 \\
7 & Lack of quality bull at village level & 22.17 & 16.67 \\
8 & High cost of treatment of reproductive disorders & 19.50 & 9 \\
9 & Non-availability of pasture or grazing land in village & 20.00 & 9 \\
10 & Less scope for availability of green fodder throughout year & & \\
11 & Lack of demand driven development programmes/policy/ & & \\
& support/ incentives for reproductive management of dairy animals & & \\
\hline
\end{tabular}


were found to be the two best strategies for faster dissemination of information regarding management of reproductive problems. Hence two strategies namely Booklet and video were developed for managing reproductive problems in dairy animals.

The effectiveness of extension strategies was assessed in Dilawara, Chundipur and Dhakwada villages of Karnal district with 20 respondents each. Table 3 depicts the knowledge of respondents before and after exposure of different extension strategies. It can be observed from Table 3 that the mean knowledge score about managing reproductive problem was 46.70 in Dilawara village before the distribution of booklet which increased to 56.06 after the T1. In Chundipur village, the mean knowledge score of the respondents about managing reproductive problem got enhanced from 44.25 to 55.80 before and after the exposure of video to respondents. In case of Dhakwada village, before the treatment (T3), the mean score was observed to be 44.95 which changed to 58.20 after the exposure of both video and booklet. It could be seen from Table 2 that there was change in mean knowledge score of respondents in all the three villages by the means of $\mathrm{T} 1, \mathrm{~T} 2$ and $\mathrm{T} 3$.

The knowledge gain in managing reproductive problems was assessed after exposure to different extension strategies. The knowledge gain of the respondents was calculated by taking the pre exposure score and post exposure score. Difference in pre and post exposure score was taken as an indicator for effectiveness of extension strategies. The mean gain in knowledge also expressed in terms of percentage of knowledge gain. The mean knowledge gain was 10.75 per cent by the exposure of T1 whereas after exposure of T2 the mean knowledge gain was 13.28 per cent. The mean knowledge gain was found to be 15.23 per cent after exposure of both Video + Booklet (T3). It could be observed from Table 4 that all the treatments proved to be effective in achieving higher knowledge gain among the respondents as the overall gain in knowledge through different extension strategies was found to be statistically significant at percent level of significance. Hence, all the three treatments were effective in imparting knowledge with considerable variation in their level of effectiveness.

Knowledge level of respondents was seen to increase after the use of all the strategies. The Booklet in Dilawara village might have influenced the respondents to gain more knowledge about management of reproductive problems. Booklet which was developed was very comprehensive, containing sufficient information about eight main reproductive problems of dairy animals with related visuals so respondents might have found it very useful for knowledge enhancement. The study on effectiveness of cattle and buffalo expert system in Salem district of Tamil Nadu by Ponnusamy et al. (2016) revealed that that the medium size farmers gained 15.77 per cent, large size farmers 15.17 per cent, practising farm women 14.94 per cent marginal and small farmers gain 13.80 per cent of knowledge due to exposure to the expert system.

The demonstration of Video in Chundipur village might have aroused the interest and curiosity of respondents regarding management of reproductive problems in dairy animals as the video was made in very simple in language, no jargons were used, containing all the comprehensive information about the reproductive management of dairy animals and thereby boosting up their confidence and knowledge about the same. These findings are in line with Vidya et al. (2010) who found that educational interactive video (DVD) was highly effective in achieving higher knowledge gain among the respondents in dairy health management practices.

The combinations of two strategies in the Dhakwala village, showed a very obvious increase in the mean score of the respondents. It was found that all the three treatments have been effective in imparting knowledge on the subject matter. However, it can be observed from the means that all the three treatments were not equal in imparting knowledge. The T3 was found highly effective followed by T2 and T1 with mean knowledge gain of $15.23,13.28$ and 10.75 percent respectively after exposure. This might be due to reinforcement of the same message through different channels to reach the respondents. Treatment 3 involves more number of senses i.e., the sense of seeing, hearing and reading. The very fact that involvement of more number of senses allows people to grasp more information within stipulated time is supportive of the result.

\section{Ranking of constraints perceived by dairy farmers}

The constraints of farmers were mentioned in Table 5. The weighted mean score was calculated and the constraints were ranked accordingly. Poor veterinary facilities during emergency hours with weighted mean score 27.83 was ranked as first constraints faced by farmers. It is generally seen that most of the veterinary surgeons/ doctors avoid staying at village level. Due to lack of infrastructure facilities in rural areas, they generally prefer to live in nearby cities. Therefore, they might not be available at time of emergency hours. During the personal interaction with veterinary Surgeons (VS) and Veterinary Livestock Development Assistants (VLDA), it was found that area of jurisdiction was very large as only 728 posts were filled against 1108 sanctioned posts in case of VS and 2485 posts were filled against 3051 sanctioned posts in case of VLDA as a result the ratio of veterinary field officer to total number of animals was very poor, hence it was difficult to handle every case at farmers doorstep (Government of Haryana, 2018). Lack of good quality bull at village level (25.17) was the second most serious constraint. Respondents revealed that there was lack of quality bull at village level although there was availability of scrub bulls but they are not progeny tested bulls. So most of the respondents prefer AI method due to its easy accessibility although they felt that the 
conception rate was very poor as compared to natural breeding in their animals. This problem also identified by Meena and Malik (2009) in Karnal district of Haryana. Poor conception rate with AI (24.33) was ranked third constraint of dairy farmers of Karnal district of Haryana. This might be due to lack of well trained staff for performing artificial insemination (AI) or poor quality of semen. The other important constraints were non-availability of $\mathrm{AI}$ and PD services at door step with weighted mean score 23.15, high cost of treatment of reproductive problems (22.17), lack of trained professionals for $\mathrm{AI}$ as well as for handling of reproductive problems in the locality (22.00) and economic loss due to decreased reproductive efficiency after occurrence of any reproductive diseases (22.00).

\section{Conclusions}

Reproductive problems pose major challenges in attaining productivity and profitability in dairy ventures. Appropriate extension strategies considering the need and relevance to the farmers of particular locality or region could play a major role to eduacte farmers on different aspects of management of reproductive problems in dairy animals which can ultimately minimise the economic loss of farmers due to these problems. The study vividly explains the knowledge gain of respondents after exposure to Video and Booklet, which could be further improved after subsequent exposure and providing detailed information to the farmers. Among all the three treatments, video + booklet emerged as most effective method in communicating the knowledge of reproductive management of dairy animals. Thus, the potentialities of this treatment could be best exploited in training programmes of farmers, by field extension functionaries and other stakeholders of dairy farming including State Departments of Animal Husbandry, Krishi Vigyan Kendra (KVK), Agriculture Technology Information Centre (ATIC), Agriculture Technology Management Agency (ATMA), Farmers Training Centers (FTC) and commodity groups.

\section{References}

Arthur GH (1975) Veterinary reproduction and obstetrics. The Macmillan Publishing Company Inc. New York. 4th Ed. 383-446

English HB, English AC (1961) Comprehensive dictionary of psychological analytical items. Green\& company, Longman's New York
Government of Haryana (2018).http://www.pashudhanharyana.gov.in/ employee-corner/staff-position

ICAR (2013) Handbook of Animal Husbandry, Fourth edition. :506

Keown JF, Larson LL and Kononoff PJ (2006) Dairy health management for optimum production and reproductive performance. Neb Guide: Dairy herd management.

Khan HM, Bhakat M, Mohanty TK, Gupta AK, Raina VS, Mir MS (2009) Peripartum reproductive disorders in buffaloes- An overview. Vetscan 4(2): 38

Kumar AS, Yasotha A (2015) Correction and management of total uterine prolapse in a crossbred cow. Journal of Agriculture and Veterinary Sciences 8(1):14-16

Kumar PR, Shukla SN, Purkayastha RD (2013) Economical analysis of the estimated cost of management of anestrus buffaloes under field conditions using different hormonal and non-hormonal strategies. Journal of Animal Health and Production 1(4): 39-41

Kumaresan A, Srivastava AK, Mohanty TK, Prashad S (2012) Reproductive disorders and their management in dairy cattle and buffalo. Book by Livestock Production and Management in NDRI.

Lobago F, Bekana M, Gustafsson H, Kindahl H (2006) Reproductive performances of dairy cows in smallholder production system in Selalle, Central Ethiopia. Tropical Animal Health and Production 38: 333-342.

Meena MS, Malik BS (2009) Participatory identification of reproductive problems among dairy animals and constraints faced by farmers in Haryana.Indian Journal of Animal Sciences79 (11): 1172-1175

Pawshe CH, Ingawale MV, Deshmukh SG, Munde VK, Pawshe MD (2011) Estrus synchronization in bovine: present status and future prospect. In: National Symposium on Reproductive Biotechnology for Augmenting Fertility and Conservation of Animal Species with special reference to North Eastern hilly region, Selesih, Aizwal, Mizoram.

Ponnusamy K (2006) Multidimensional Analysis of integrated Farming System in the Coastal Agro-Eco System of Tamil Nadu. Ph.D. Thesis. NDRI Deemed University, Karnal, Haryana.

Ponnusamy K, Sriram K, Prabhukumar S, Vadivel E, Venkatachalam R, Mohan B (2016) Effectiveness of cattle and buffalo expert system in knowledge management among the farmers. Indian Journal of Animal Sciences 86(5): 604-608.

Simerl NA, Wilcox CJ, Thatcher WW (1992) Postpartum performance of dairy heifers freshening at young ages. Journal of Dairy Sciences 75: 590-595.

Srivastava AK, Kumaresan A, Patil GR (2015) SAARC Dairy Outlook.Natundhara Printing Press. Dhaka, Bangladesh. ISBN- 978984-33-9790-4.

Vidya P, Manivannan C, Kumar SN (2010) Effectiveness of an Educational Interactive Video-DVD on Dairy Health Management Practices in Terms of Knowledge Gain among Dairy Farmers. The Online Journal of Rural Research and Policy 5(7): 1- 17 